\title{
GERAKAN SADAR LINGKUNGAN MASYARAKAT DESA TONGKE- TONGKE DALAM MENGATASI TERJADINYA ABRASI DAN PASANG AIR LAUT DI KABUPATEN SINJAI
}

\author{
Irvandi $^{1}$ \\ ${ }^{1}$ Universitas Muhammadiyah Makassar \\ irvandisykr98@gmail.com
}

\begin{abstract}
Abstrak
Hutan mangrove salah satu lahan yang kelestariannya akan terancam dan akan menjadi salah satu isu lingkungan global. Terjadinya peningkatan kecenderungan pengrusakan ekosistem hutan mangrove dengan meningkatnya kebutuhan hidup masyarakat lokal, seperti kebutuhan rumah tangga, penebangan hutan mangrove yang dijadikan kayu bakar. Terjadinya abrasi di Kabupaten Sinjai ini disebabkan oleh ulah manusia yang tidak sadar akan pentingnya mangrove bagi kehidupan masyarakat dan bahkan dapat mengakibatkan terjadinya pasang air laut. Oleh karena itu, penulis membuat sebuah program dengan judul Gerakan Sadar Lingkungan Masyarakat Desa Tongke-Tongke dalam Mengatasi Terjadinya Abrasi dan Pasang Air Laut di Kabupaten Sinjai. Metode yang digunakan yaitu dengan koordinasi, sosialisasi program, pembuatan video teknis pelaksanaan program hingga penyusunan laporan dan publikasi. Analisis data yang digunakan yaitu menggunakan data primer. Ketercapaian target yang telah dilaksanakan berkisar sebesar 95\% dari seluruh rangkaian kegiatan. Program terlaksana dengan pemberian materi kepada mitra mengenai program yang juga akan menjadi pelaksana keberlanjutan program. Materi mengenai rehabilitasi mangrove, dampak dan manfaat mangrove. Sebagai pedoman keberlanjutan program, masyarakat diberikan buku pedoman pelaksanaan program yang dilengkapi modul. Buku pedoman sudah didaftarkan Hak Kekayaan Intelektual (HKI). Adapun tahapan rencana berikutnya yaitu Melakukan Follow up sebagai bentuk untuk menjalin komunikasi, sekaligus mengontrol pelaksanaan program gerakan sadar lingkungan atau rehabilitasi mangrove.
\end{abstract}

Kata Kunci : Gerakan Sadar Lingkungan, Hutan Mangrove, Abrasi dan Pasang Air Laut

\section{PENDAHULUAN}

Hutan mangrove salah satu lahan yang kelestariannya akan terancam dan akan menjadi salah satu isu lingkungan global. Terjadinya peningkatan kecenderungan pengrusakan ekosistem hutan mangrove dengan meningkatnya kebutuhan hidup masyarakat lokal, seperti kebutuhan rumah tangga, penebangan hutan mangrove yang dijadikan kayu bakar, serta meningkatnya aktivitas pencari kepiting ke wilayah ekosistem mangrove yang memicu peningkatan kerusakan hutan mangrove (Raman, dkk. 2015). Akibat dari kerusakan yang di lakukan membuat air laut dapat mengikis pantai atau biasa dikatakan sebagai abrasi. Abrasi merupakan pengikisan daratan yang disebabkan oleh terjadinya pasang surut air laut, gelombang yang tinggi sehingga mengakibatkan penurunan 
permukaan tanah dan bahkan terjadi tergenangnya air laut yang dapat merubah garis pantai (Damayanti. 2013). Pantai yang tadinya terkikis (abrasi) itu karena tidak adanya atau berkurangnya pohon bakau (mangrove) yang dapat menahan gelombang, pasang surut air laut yang terjadi. Akibat lain yang ditimbulkan dari adanya abrasi sehingga mengakibatkan turunnya permukaan tanah menjadikan air pasang bisa naik hingga ke jalan atau bahkan adanya air pasang yang masuk di sekitar rumah masyarakat.

Masuknya air di sekitar rumah masyarakat membuat warga resah karena menimbulkan kerusakan pada permukaan tanah, dan bahkan pada rumah masyarakat. Terjadinya abrasi dan pasang air laut di Kabupaten Sinjai ini disebabkan oleh ulah manusia yang tidak sadar akan pentingnya mangrove bagi kehidupan masyarakat. Pelestarian mangrove perlu di lakukan oleh masyarakat khusunya masyarakat desa Tongke-Tongke Kabupaten Sinjai. Peran Pemuda sangat dibutuhkan dalam pelestarian mangrove, karena pemuda salah satu tongkat estafet para penerus dalam melestarikan dan tetap mempertahan hutan mangrove atau hutan bakau ini. Keresahankeresahan tersebut karena warga setempat yang masih kurang paham mengenai pentingnya pohon bakau/mangrove untuk mencegah yang namanya abrasi dan masuknya air pasang hingga ke jalan. Maka dari itu, penulis membuat sebuah program suatu pemberian pengetahuan mengenai lingkungan yang baik serta pengelolaan bahwa pentingnya pohon mangrove dalam mencegah atau mengatasi terjadinya abrasi dan pasang air laut yang sampai ke jalan dan pemukiman warga, dengan judul dari program ini adalah "Gerakan Sadar Lingkungan Masyarakat Desa Tongke-Tongke dalam Mengatasi Terjadinya Abrasi dan Pasang Air Laut di Kabupaten Sinjai”.

Upaya-upaya yang akan terus dilakukakan demi menjaga kelestarian hutan mangrove. Adanya program seperti ini akan membantu masyarakat dalam menyelesaikan permasalahan yang sering terjadi dalam kehidupannya. Program ini akan menyadarkan masyarakat terkhusus pemuda-pemudi desa Tongke-Tongke dalam mengatasi terjadinya abrasi dan pasang air laut. Diharapkan dalam terlaksananya program ini tidak berhenti sampai disini, melainkan akan terus berlanjut sampai mangrove tetap ada dan akan menjadi icon tersendiri di kabupaten Sinjai khususnya di Desa Tongke-Tongke, dan menjadikan masyarakat lebih sejahtera dan membantu dalam memenuhi kebutuhan ekonominya karena memanfaatkan biota laut yang hidup di sekitar mangrove. Sehingga dengan berkembannya mangrove atau hutan bakau ini akan membuat masyarakat terhindar yang namanya abrasi dan pasang air laut masuk ke jalan serta masuk disekitar rumah masyarakat lagi.

Berdasarkan uraian di atas, tujuan yang diharapkan dari program ini diantaranya:

1. Meningkatkan pertumbuhan Pohon Mangrove

2. Tetap Melestarikan Pohon Mangrove sebagai kekayaan yang dimiliki Kabupaten Sinjai.

3. Menjadikan warga Desa Tongke-Tongke lebih mengetahui pentingnya pohon Mangrove dalam lingkungan.

4. Warga Desa Tongke-Tongke memiliki keterampilan dalam mengelola kembali pohon mangrove dan tidak melakukan hal-hal yang dapat merusak pohon mangrove tersebut.

\section{METODE}

Metode pelaksanaan program Gerakan Sadar Lingkungan Masyarakat Desa TongkeTongke dalam Mengatasi Terjadinya Abrasi dan Pasang Air Laut di Kabupaten Sinjai. Program dilakukakan secara daring dan juga tahap realisasi yang dilakukan/diikuti oleh pemuda/pemudi, Desa Tongke-Tongke.

Maka dari itu berikut perincian dalam metode pelaksanaan program Gerakan Sadar Lingkungan adalah sebagai berikut:

1. Koordinasi

Koordinasi dilakukan dengan maksud mengatur strategi pelaksanaan program, diskusi dengan dosen Pendamping dilakukan melalui chat WhatsApp dengan membahas langkahlangkah dan proses pelaksanaan program yang dilakukan secara daring. Koordinasi yang dilakukan mengenai susunan metode dan program Gerakan Sadar Lingkungan yang akan diterapkan. Selanjutnya koordinasi dilakukan dengan salah satu perwakilan dari mitra yang 
membahas mengenai teknis dari sosialisasi. Segala koordinasi dilakukan melalui daring.

2. Sosialisasi Kegiatan

Sosialisasi Program dilaksanakan untuk memberitahukan kepada mitra mengenai akan dilaksanakannya Program Gerakan Sadar Lingkungan. Pada sosialisasi juga akan dibahas mengenai teknis pelaksanaan Gerakan Sadar Lingkungan atau proses pelatihan Rehabilitasi mangrove. Tim dan mitra menetapkan bersama waktu pelaksanaan program dan menyepakatinya. Tim memberikan gambaran umum mengenai program, serta menyampaikan kepada masyarakat agar mengajak masayarakat yang lainnya ikut serta dalam program atau proses pelatihan rehabilitas mangrove di Desa Tongke-Tongke Kabupaten sinjai.

3. Penyusunan Buku Pedoman

Buku pedoman pada program ini bertujuan untuk mengarahkan masyarakat Desa Tongke-Tongke agar sadar dan tetap melestarikan hutan mangrove atau hutan bakau tersebut. Penyusunan dilakukan oleh salah satu tim yang sudah di bagikan apa yang telah di amanahkan untuk dikerjakan. Pembuatan di awali dengan pengumpulan bahan-bahan buku pedoman yang di searching di google. Kemudian melakukan penyusunan, ketika pengumpulan bahan telah selesai dilakukan. Setelah bahan buku pedoman telah di susun langkah selanjutnya adalah finalisasi yaitu dengan mengecek kembali buku pedoman yang telah disusun. Terakhir tim pelaksana membuat sebuah desain sampul buku pedoman yang kemudian di gabung dalam satu susunan yang rapi.

4. Penyusunan Modul

Berbeda dengan buku pedoman, modul di buat sebagai buku yang berisi materi pelatihan, penanaman ilmu pengetahuan kepada masyarakat Desa Tongke-Tongke terkhusus kepada mitra dalam program ini. Modul berisi bagaimana pentingnya hutan mangrove, manfaat dan fungsi bagi kehidupan masyarakat, dampak menebang atau merusak mangrove, dan juga berisi mengenai pelestarian hutan mangrove itu sendiri untuk masyarakat Desa Tongke-Tongke.

5. Pelaksanaan Program

Proses pelaksanaan program Bakko Sinjai yang pertama kali dilakukan adalah menghubungi mitra program ini. Mitra dalam program ini yaitu Karang Taruna Desa TongkeTongke. Tim menghubungi langsung ketua Karang Taruna Bapak Edy Syukri, S.pd., M.pd melalui aplikasi WhatsApp untuk menanyakan kesiapannya dalam mengikuti dan memberikan sambutan langsung pada saat pembukaan pelaksanaan program Bakko Sinjai secara virtual. Pelaksanaan program Bakko Sinjai bukan hanya di ikuti oleh anggota Karang Taruna tetapi juga diikuti oleh beberapa pemuda-pemudi Desa Tongke-Tongke. Pelaksanaan progam dilakukan secara virtual lewat aplikasi Zoom. Pelaksanaan program lewat zoom dimbil alih pertama kali oleh tim yang ditugaskan sebagai moderator, lanjut pembacaan ayat suci $\mathrm{Al}$ quran, kemudin sambutan oleh ketua Karang Taruna Desa Tongke-Tongke, terakhir yaitu pembawaan materi mengenai program Bakko Sinjai oleh tim yang sudah ditugaskan.

6. Pembuatan Video

Pembuatan video dimaksudkan untuk mempermudah mitra dalam pelaksanaan program untuk keberlanjutannya. Video berisi mengenai rangkaian proses pelaksanaan program dari koordinasi hingga potensi keberlanjutannya. Video pelaksanaan ini nantinya akan dipublikasikan tim pelaksana melalui akun Youtube Gerakan sadar Lingkungan Desa Tongke-Tongke Kabupaten sinjai.

7. Penyusunan laporan

Laporan diperlukan sebagai pertanggungjawaban hasil dari program yang telah dicanangkan. Laporan juga dapat digunakan tim pelaksana sebagai tolak ukur hasil yang dicapai dan potensi dalam keberlanjutannya. Hal ini menjadi semangat tersendiri bagi tim untuk bisa bermanfaat kepada sesama. 


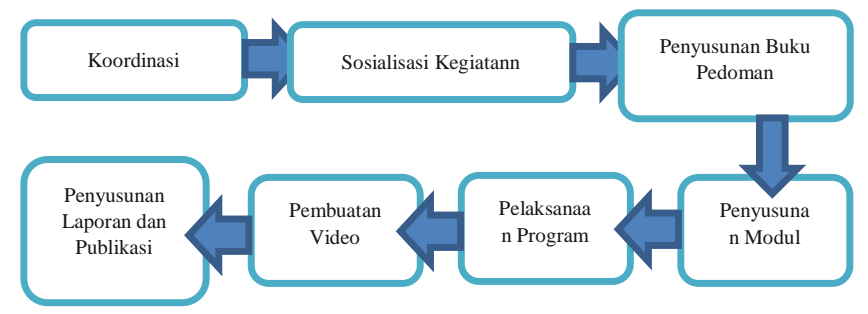

Gambar 1. Flow map Metode Pengembangan

\section{HASIL DAN PEMBAHASAN}

Pelaksanaan program Gerakan Sadar Lingkungan berdasarkan ketercapaian target berkisar 95\% dari keseluruhan rangkaian kegiatan program, yang terdiri dari koordinasi, membuat buku dan modul pelaksanaan, sosialisasi serta pembuatan video pelaksanaan program. Adapun rincian metode pelaksanaan yang telah dilakukan oleh anggota tim pelaksana, dosen pendamping bersama dengan mitra dan masyarakat Desa Tongke-Tongke Kabupaten Sinjai melalui via daring dapat dilihat pada Tabel 4.1 sebagai berikut:

\begin{tabular}{|c|c|c|c|c|}
\hline Kegiatan & Keterangan & $\begin{array}{l}\text { Persentase } \\
\text { Pencapaian } \\
\text { per Item }\end{array}$ & $\begin{array}{l}\text { Persentase } \\
\text { dari } \\
\text { Keseluruha } \\
\text { n Kegiatan }\end{array}$ & Hasil Kegiatan \\
\hline $\begin{array}{l}\text { Persiapan } \\
\text { /Koordin } \\
\text { asi }\end{array}$ & $\begin{array}{l}\text { Mengatur strategi yang di } \\
\text { akan dilaksanakan pada } \\
\text { Program }\end{array}$ & $100 \%$ & $2 \%$ & $\begin{array}{l}\text { Telah dilakukan koordinasi } \\
\text { dengan anggota tim secara } \\
\text { daring terkait pembagian } \\
\text { tugas berdasarkan arahan } \\
\text { dosen }\end{array}$ \\
\hline $\begin{array}{l}\text { Pembuata } \\
\text { n buku } \\
\text { pedoman } \\
\text { pelaksana } \\
\text { an dan } \\
\text { modul } \\
\text { jaga dan } \\
\text { lestarikan } \\
\text { mangrove }\end{array}$ & $\begin{array}{l}\text { Mengumpulkan referensi } \\
\text { terkait dengan rehablitasi } \\
\text { mangrove serta mencari } \\
\text { referensi mengenai } \\
\text { mangrove }\end{array}$ & $100 \%$ & $30 \%$ & 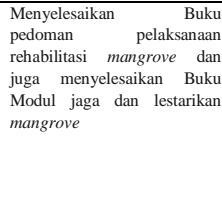 \\
\hline $\begin{array}{l}\text { Sosilisasi } \\
\text { Online } \\
\text { Gerakan } \\
\text { Sadar } \\
\text { Lingkung } \\
\text { an } \\
\end{array}$ & $\begin{array}{lr}\text { Memberikan } & \text { gambaran } \\
\text { kepada } & \text { masyarakat } \\
\text { terkait hal teknis program }\end{array}$ & $100 \%$ & $40 \%$ & $\begin{array}{l}\text { Telah dilaksanakan sesuai } \\
\text { dengan jadwal yang telah } \\
\text { dicanangkan }\end{array}$ \\
\hline $\begin{array}{l}\text { Pelaksana } \\
\text { an } \\
\text { Program/ } \\
\text { Pelatihan } \\
\text { rehabilita } \\
\text { si } \\
\text { mangrove }\end{array}$ & $\begin{array}{lr}\text { Pemahaman } & \text { dan } \\
\text { penguatan Masyarakat } \\
\text { terkait dengan hutan } \\
\text { mangrove }\end{array}$ & $100 \%$ & $60 \%$ & $\begin{array}{l}\text { Telah dilaksankan sesuai } \\
\text { dengan jadwal yang telah } \\
\text { dicanangkan }\end{array}$ \\
\hline $\begin{array}{l}\text { Pembuata } \\
\text { n Video } \\
\text { pelaksana } \\
\text { an PKM } \\
\text { M Bakko } \\
\text { Sinjai }\end{array}$ & $\begin{array}{ll}\text { Persiapan bahan } & \text { untuk } \\
\text { penyusunan } & \text { video } \\
\text { pelaksanaan PKM } & \end{array}$ & $100 \%$ & $80 \%$ & $\begin{array}{l}\text { Setiap anggota tim ditugaskan } \\
\text { mengumpulkan bahan-bahan } \\
\text { pembuatan video seperti } \\
\text { video kabupaten sinjai, desa } \\
\text { Tongke-Tongke, script narasi, } \\
\text { dan rekaman van video } \\
\text { pendampingan ke mitra serta } \\
\text { video rekaman pelaksanaan }\end{array}$ \\
\hline
\end{tabular}

\begin{tabular}{|l|l|l|l|l|}
\hline & & & & $\begin{array}{l}\text { pelatihan } \\
\text { mangrove }\end{array}$ \\
\hline Mendafta & \multicolumn{2}{|c|}{ Mempatenkaniliasi } \\
rkan buku & pedoman pelaksanaan & $100 \%$ & $95 \%$ & \\
Buku & program & & & \\
Pedoman & & & & \\
Hak & & & & \\
Kekayaan & & & & \\
Intelktual & & & \\
(HKI) & & & \\
\hline
\end{tabular}

Di bawah ini adalah identifikasi ketercapaian ditinjau dari luaran program:

1. Pelatihan Tentang Rehabilitasi Mangrove di Desa Tongke-Tongke, Kabupaten Sinjai

Pelatihan telah dilaksanakan pada hari jumat tanggal 18 September 2020 dengan peserta pelatihan dari masyarakat dan pemudapemudi Desa Tongke-Tongke yang tergabung dalam organisasi Kepemudaaan yaitu Karang Taruna Desa Tongke-Tongke. Program ini juga bekerja sama dengan organisasi Karang Taruna Desa Tongke-Tongke sebagai organisasi yang ada di Desa Tongke-Tongke. Program ini dihadiri langsung oleh Ketua Karang Taruna Bapak Edy Syukri. Pada pelatihan ini ketua Karang Taruna yang memberikan sambutan untuk pembukaan pelatihan rehabilitasi Mangrove. Kemudian pada pembicara pelatihan kali ini yaitu dari tim pelaksana Gerakan Sadar Lingkungan yang membawakan dua materi yaitu: 1. Pengenalan mengenai mangrove, dampak, fungsi dan manfaat, dan cara pelestarian Mangrove melalui buku modul jaga dan lestarikan Mangrove. 2. Pemaparan mengenai rehabilitasi mangrove.

Dalam pelatihan ini peserta akan dibekali buku modul dan buku pedoman rehabilitasi mangrove. Bahkan masyarakat Desa Tongke-Tongke akan mendapatkan ilmu pengetahuan mengenai pentingnya mangrove, dan cara pelestarian yang baik, yang di jelaskan dalam buku pedoman Rehabilitasi Mangrove agar kehidupan masyarakat Desa TongkeTongke sejahtera. Pelaksanaan pelatihan berlangsung dengan baik dan tertib karena masyarakat dan pemuda-pemudi Desa TongkeTongke tertarik dengan tema yang kami angkat mengenai rehabilitasi mangrove.

2. Terbentuknya Masyarakat yang Memberdayakan Lingkungan Sekitar

Ekonomi, Sosial, dan Budaya 
Setelah terlaksananya pelatihan rehabilitasi mangrove kepada masyarakat dan pemuda-pemudi Desa Tongke-Tongke. Masyarakat dan pemuda-pemudi aktif melakukan rehabilitasi mangrove seperti melakukan survei buah mangrove, pemetikan atau pemilihan buah mangrove yang layak untuk ditanam, dan terakhir melakukan penanaman mangrove pada kawasan yang layak untuk ditanami buah mangrove.

3. Terbentuknya Komunitas BAKKO SINJAI

Komunitas Bakko Sinjai sebagai komuitas pemuda desa Tongke-tongke dalam merawat dan melestarikan hutan mangrove, yang terbentuk pada tanggal 30 September 2020. Aidil fitra sebagai ketua dalam komunitas ini. Aidil terpilih sebagai ketua karena di percayakan mampu mengarahkan pemudapemudi desa Tongke-Tongke untuk dapat melestarikan dan menjaga hutan mangrove atau hutan bakau yang ada di Desa Tongke-Tongke, Kabupaten Sinjai. Komunitas ini dibentuk agar mangrove selalu terjaga dan dapat tetap lestari, apalagi komunitas ini dihuni oleh para pemuda Desa Tongke-Tongke sebab pemuda adalah generasi yang dapat membawa perubahan. Diharapkan dengan terbentuknya komunitas Bakko Sinjai ini tidak ada lagi permasalahan yang terjadi terkait dengan adanya abrasi dan pasang air laut yang bisa naik hingga ke jalan dan disekitar rumah masyarakat Desa TongkeTongke.

4. Terbentuknya Pemuda yang Terampil dalam Berwirausaha

Program Gerakan sadar lingkungan ini merupakan program yang dapat memberikan keuntungan bagi masyarakat atau pemuda yang tinggal d sekitar tumbuhnya hutan mangrove. Pengoptimalan dalam program ini dengan selalu menjaga dan melestarikan hutan manrove, selain dapat terhindar dari abrasi dan pasang air laut naik hingga ke jalan pemuda dapat memanfaatkan buah mangrove sebagai sumber tambahan dalam ekonominya. Pemuda memanfaatkan buah mangrove untuk dijual kepada masyarakat lainnya untuk di tanam di daerah tersebut. Bukan hanya itu hasil laut atau biota laut yang hidup di sekitar hutan mangrove atau hutan bakau juga dimanfaatkan pemuda untuk diualnya kepada masyarakat sekitar di Desa Tongke-Tongke.

Adapun beberapa rincian kegiatan program Gerakan Sadar Lingkungan Masyarakat Desa Tongke-Tongke dalam Mengatasi Terjadinya Abrasi dan Pasang Air Laut di Kabupaten Sinjai, adalah sebagai berikut.

1. Buku Pedoman Pelaksanaan Program

a. Pembuatan sampul buku pedoman pelaksanaan oleh anggota tim

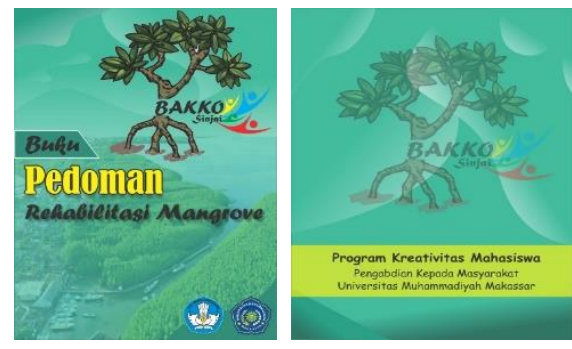

Gambar 2. Hasil desain sampul buku pedoman

b. Pembuatan buku pedoman pelaksanaan program, agar pemuda/pemudi di Desa Tongke-Tongke Kabupaten Sinjai dapat menjalankan program rehabilitasi mangrove Bakko Sinjai di daerah pesisir pantai.

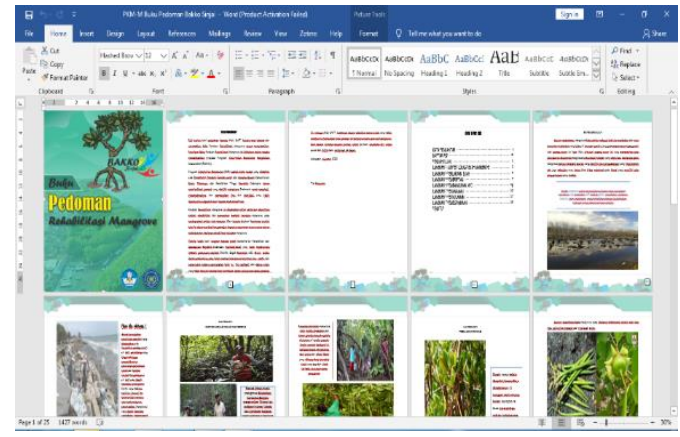

Gambar 3. Proses pembuatan buku pedoman pelaksanaan

c. Pembuatan modul yang dapat digunakan sebagai salah satu referensi atau rujukan bagi masyarakat Desa Tongke-Tongke. 


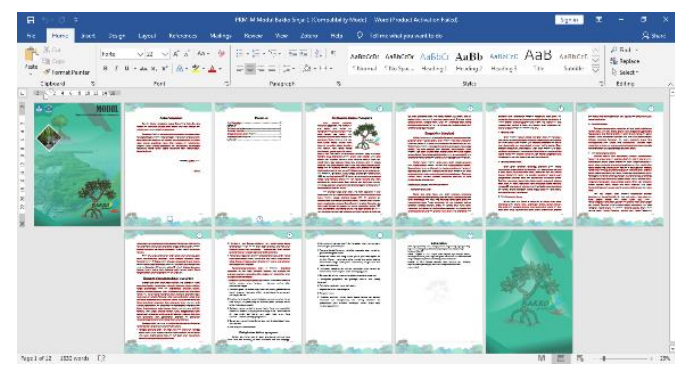

Gambar 4. Pembuatan modul

d. Setelah pembuatan buku pedoman pelaksanaan program dan modul, anggota tim menjalin komunikasi dengan pemuda/pemudi Desa Tongke-Tongke serta mengirimkan buku pedoman dan modul dalam bentuk pdf.

2. Realisasi Program

Pelaksanaan realisasi program Gerakan Sadar Lingkungan telah dilaksanakan pada tanggal 18 September 2020. Realisasi program yang dilaksanakan berupa pelatihan dan pemberian materi mengenai pentingnya hutan mangrove dan tata cara melakukan rehabilitasi mangrove di pesisir pantai kepada pemuda/pemudi Desa Tongke-Tongke melalui aplikasi Zoom Meeting. Ketua Karang Taruna Mangrove Desa Tongke-Tongke, Edi Syukri, turut hadir serta memberikan sambutan pada saat pelaksanaan realisasi program tersebut.

Upaya menjaga kelestarian hutan mangrove dapat dilakukan oleh masyarakat sekitar hutan dengan memelihara ekosistem mangrove sehingga terjaga kelangsungan hidupnya. Pendekatan secara buttom up merupakan suatu teknik dalam rehabilitasi hutan mangrove. Seyogyanya upaya pemulihan hutan mangrove adalah atas biaya pemerintah, sedangkan perencanaan, pelaksanaan, evaluasi keberhasilan dan pemanfaatannya secara berkelanjutan semuanya dipercayakan kepada masyarakat (Lugina, dkk. dalam Nanlohy, L. H., \& Masniar, M. 2020). Namun dengan adanya program Pengabdian Kepada Masyarakat yang dilakukan oleh mashasiswa Universitas Muhammadiyah Makassar dapat sedikit memberikan gambaran dan manfaat dari rehabilitasi mangrove di Desa Tongke-Tongke.

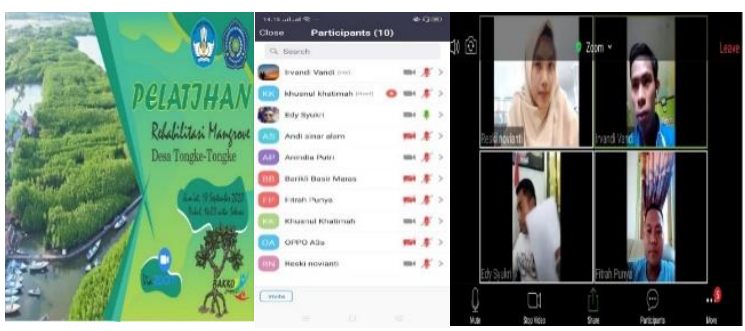

Gambar 5. Proses pelaksanaan pelatihan rehabilitasi mangrove via zoom

3. Potensi Khusus

Aspek terpenting dalam program pengabdian masyarakat adalah pada potensi khusus. Pemuda-pemudi Desa Tongke-Tongke akan selalu berperan aktif dalam menjaga dan melestarikan hutan mangrove, karena pemudapemudi Desa Tongke sudah dibekali dengan penanam ilmu pengetahuan mengenai rehabilitasi mangrove dan pelestarian mangrove. usaha-usaha yang dilakukan oleh tim realisasi Bakko Sinjai ini merupakan salah satu usaha transfer leadership kepada para masyarakat dan pemuda di Desa TongkeTongke, Kabupaten Sinjai agar mangrove dapat tetap lestari. Potensi Khusus dalam program Bakko Sinjai juga mampu mendukung beberapa aspek kehidupan yaitu:

a) Aspek Lingkungan

Setelah masyarakat dan pemuda diberikan pengetahuan tentang cara pelestarian hutan mangrove masyarakat ataupun pemuda melakukan pemilihan buah mangrove yang kemudian akan dilakukan penanaman. Ini bertujuan agar nantinya tidak akan ada lagi dampak yang ditimbulkan dari adanya abrasi dan pasang air laut di Desa Tongke-tongke sehingga ekosistem jadi lebih baik. Menurut Sumanto (2020). Ekosistem mangrove mempunyai fungsi dan manfaat yang serba guna dan keunikannya sebagai kawasan peralihan antara daratan dan lautan menjadikan kawasan vegetasi mangrove 
sasaran pembangunan berbagai sektor. Keberadaan kawasan vegetasi mangrove di daerah pasang surut yang lingkungannya mendukung kegiatan perikanan menyebabkan kawasan ini banyak dimanfaatkan untuk usaha pertambakan dengan mengorbankan vegetasi mangrove.

Menurut Pratiwi, N. A., \& Alhadi, Z. (2020). Fungsi hutan mangrove dalam melindungi serta melestarikan kawasan pesisir dapat dilihat secara ekologis yaitu,

1. Dapat melindungi kehidupan dibelakang garis pantai dari gelembang tsunami, abrasi dan angin, serta mencegah terjadinya salinisasi pada wilayah yang ada dibelakngnya, karena keadaan akarnya yang kuat serta rapat mampu menggenggan dan menstabilkan habitat tumbuhnya, dan keadaan tajuk yang relative rapat.

2. Karena sistem akarnya yang dapat menahan lumpur sungai dan menyerap berbagai bahan pollutan, sehingga dapat melindungi padang lamun dan juga terumbu karang yang secara ekologis akan dapat pada akhirnya melindungi kehidupan berbagai jenis flora dan fauna yang beradaptasi dengan padang lamun dan terumbu karang.

3. Banyak manusia yang membutuhkan mangrove sebagai mata pencariannya, seperti mencari ikan kecil, udang, kepiting, maupun dimanfaatkan sebagai bahan untuk obat-obatan, selain itu melindungi tempat buaya dan berlindungnya berbagai jenis udang komersial, ikan-ikan, dan juga termasuk melindungi tempat tinggal baik tetap maupun sementara berbagai jenis burung-burung, mamalia, kepiting, ika,udang dan reptile, yang paling banyak diantaranya termasuk jenis binatang yang di lindungi. b) Aspek Ekonomi

Ketika program Gerakan Sadar Lingkungan ini berhasil dan rehabilitasi berjalan dengan baik pula, maka akan banyak memberikan manfaaat dari sektor ekonominya. Begitu banyak keuntungan yang dapat dimanfaatkan oleh masyarakat atau pemuda Desa Tongke-Tongke. Diantaranya adalah memanfaatkan biotabiota laut yang hidup disekitar hutan mangrove. Bukan hanya itu buah mangrove juga dapat dimanfaatkan oleh pemuda untuk dijual kembali kepada masyarakat lainnya diluar daripada masyarakat Desa Tongke-Tongke.

c) Aspek Sosial

Upaya pelestarian ekosistem hutan mangrove yang dilakukan oleh pemerintah biasanya dilakukan oleh Kementrian Lingkungan Hidup dan Kehutanan, Kementrian Kelautan dan Perikanan maupun dari Pemerintah daerah setempat yang didukung oleh masyarakat yang berpartisipasi dalam menjaga kelestarian lingkungan alam (Litiloly, L. I., Mardiatmoko, G., \& Pattimahu, D. V. 2020). Namun dengan adanya Program Pengabdian Kepada Masyarakat ini dapat membantu masyarakat sekitar dalam merehabilitasi mangrove. Berhasilnya Desa Tongke-Tongke dalam melaksanakan Program ini, dapat menginspirasi desadesa lainnya dalam melestarikan mangrove dan tetap menjaga lingkungannya agar tatanan kehidupan masyarakat berjalan dengan baik dan masyarakat sejahtera. 


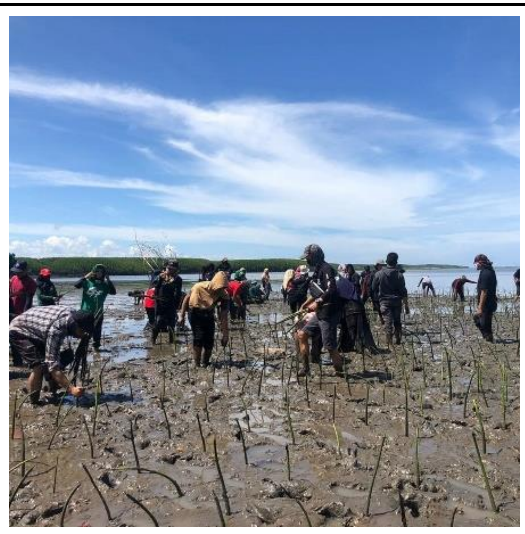

Gambar 6. Dokumentasi mandiri oleh pemuda Desa Tongke-Tongke

\section{KESIMPULAN}

Terselenggaranya Program Gerakan Sadar Lingkungan kepada masyarakat Desa TongkeTongke ini sebagai upaya dalam mengatasi abrasi dan pasang air laut melalui pelatihan rehabilitasi mangrove. Ketercapaian target yang telah dilaksanakan ditengah wabah pandemi berkisar sebesar 95\% dari seluruh rangkaian kegiatan. Ketercapaian ini meliputi terlaksananya kegiatan dari koordinasi, pembuatan dan publikasi buku pedoman pelaksanaan Pelatihan rehabilitasi mangrove, pelaksanaan Pelatihan rahabilitasi gerakan sadar lingkungan hingga pembuatan video pelaksanaan program. Program ini terlaksana dan disambut baik oleh masyarakat dan pemuda-pemudi Desa Tongke-Tongke. pelatihan dilaksanakan secara daring melauli via Zoom meeting. Pelatihan ini bertujuan agar masyarakat sadar akan penting hutan mangrove dalam kehidupan masyarakat di Desa Tongke-Tongke. Banyak manfaat yang dapat diperoleh oleh masyarakat jika hutan mangrove tetap dilestarikan diantaranya dari segi ekonomi. Program ini juga menciptakan terbentuknya Komunitas Bakko Sinjai ini betujuan agar mangrove dapat terjaga dan akan selalu dilestarikan oleh Pemuda-pemudi Desa Tongke-Tongke.

\section{UCAPAN TERIMAKASIH}

Pelaksana mengucapkan banyak terima kasih kepada:
1. Bapak Prof. Dr. Ambo Asse, M.Ag. selaku Rektor Universitas Muhammadiyah Makassar.

2. Pihak kemendikbud Republik Indonesia yang telah mewadahi mahasiswa dalam menyalurkan kemampuan menulisnya melalui kegiatan Program Kepada Masyarakat

3. Dosen Pembimbing yang telah memberikan masukan dan arahan dalam pelaksanaan program pengabdian kepada masyarakat.

4. Bapak Edy Syukri, S.Pd., M.Pd selaku mitra dalam program Gerakan Sadar Lingkungan ini.

\section{REFERENSI}

Damaywanti, K. (2013). Dampak Abrasi Pantai Terhadap Lingkungan Sosial (Studi Kasus di Desa Bedono, Sayung Demak.

Litiloly, L. I., Mardiatmoko, G., \& Pattimahu, D. V. 2020. Analisis Ekonomi Hutan Mangrove di Teluk Kotania Kabupaten Seram Bagian Barat.

Nanlohy, L. H., \& Masniar, M. (2020). Manfaat Ekosistem Mangrove Dalam Meningkatkan Kualitas Lingkungan Masyarakat Pesisir. Abdimas: Papua Journal of Community Service, 2(1), 1-4.

Pratiwi, N. A., \& Alhadi, Z. (2020). Kendala Pemerintah dalam Kegiatan Pelestarian Mangrove sebagai Sarana Pengurangan Resiko Bencana di Kota Pariaman. Jurnal Mahasiswa Ilmu Administrasi Publik, 2(3), 87-95.

Raman, R., Malik, I., \& Hamrun, H. (2015). Kemitraan Pemerintah Daerah Dengan Kelompok Masyarakat Dalam Pengelolaan Hutan Mangrove di Desa Tongke-Tongke Kabupaten Sinjai. Otoritas: Jurnal Ilmu Pemerintahan, 5(2).

Sumanto, S. (2020). Inventarisasi Tumbuhan Mangrove dalam Rangka Rehabilitasi Hutan Bakau di Pesisir Pantai Paojepe Desa Paojepe Kecamatan Keera Kabupaten Wajo Propinsi Sulawesi Selatan. Prosiding SNPBS (Seminar Nasional Pendidikan Biologi dan Saintek) Ke-5. 